\title{
Epileptic and cognitive changes in children with cerebral palsy: an Egyptian study
}

\author{
This article was published in the following Dove Press journal: \\ Neuropsychiatric Disease and Treatment \\ 29 May 2014 \\ Number of times this article has been viewed
}

\author{
Hamdy N El-Tallawy \\ Wafaa MA Farghaly \\ Ghaydaa A Shehata \\ Reda Badry \\ Tarek A Rageh
}

Department of Neurology, Assiut University Hospitals, Assiut, Egypt

Correspondence: Ghaydaa A Shehata Neurology and Psychiatry Department, Assiut University Hospitals, Assiut,

7IIII Egypt

Tel +200882297075

$\mathrm{Fax}+200882333327$

Email ghaydaa83@yahoo.com
Background: Cerebral palsy (CP) is the most frequent cause of motor handicap among children.

Aim of the study: We aim to study the relation of epilepsy in children with $\mathrm{CP}$ to various risk factors that affect the development of seizures.

Patients and methods: In a cross-sectional, descriptive, population-based, case-control study, 98 children with CP (48 children with CP with epilepsy, and 50 children with CP without epilepsy) were compared with 180 children without CP or seizures. The children lived in two regions in Egypt: the Al-Kharga District-New Valley and El-Quseir city-Red Sea. These cases were subjected to meticulous neurological assessment, brain magnetic resonance imaging, electroencephalography, and Stanford-Binet (4th edition) examination. Multinomial logistic regression was used to assess the risk factors.

Results: Epilepsy was diagnosed in $48.9 \%$ of all cases of CP. Mental subnormality was observed more frequently in children with epilepsy than in those without epilepsy (84.6\% versus $66.7 \%)$. The frequency of epilepsy was highest in patients with the spastic quadriplegic type of illness (58.3\%). Multinomial logistic regression revealed that prematurity ( $<32$ weeks of pregnancy), low birth weight $(<2.5 \mathrm{~kg}$ at birth), neonatal seizures, jaundice, and cyanosis were significantly associated with $\mathrm{CP}$ with epilepsy.

Conclusion: $\mathrm{CP}$ is associated with a high percentage of seizure disorders. Prematurity, low birth weight, neonatal seizures, cyanosis, and jaundice are significant risk factors among patients with CP with epilepsy compared to patients with CP without epilepsy or a healthy control group.

Keywords: cerebral palsy, epilepsy, risk factors, Egypt

\section{Introduction}

Cerebral palsy (CP) is the consequence of nonprogressive damage to the developing brain and consists of a number of clinical neurological syndromes of heterogeneous etiology. ${ }^{1}$ Epilepsy is one of the most common problems among patients with CP. It has been used as a marker of severity and often worsens the quality of life of patients with $\mathrm{CP}^{2,3}$

Epilepsy occurs in 15\%-60\% of children with CP; however, its clinical course is not well-defined. ${ }^{2-5}$ In our previous study at Al-Kharga District-New Valley, active epilepsy was recorded in $27(51.9 \%)$ of 52 children with $\mathrm{CP} .{ }^{6}$ The percentage of those with epilepsy was highest in patients with quadriplegia and lowest in patients with spastic diplegia and dystonic $\mathrm{CP}$.

Early prediction of intractable epilepsy would be valuable because rapid identification of patients at the highest risk level would allow physicians to consider them 
for earlier treatment with recent medications and other surgical and nonsurgical treatments, such as vagus nerve stimulation..$^{8,9}$

According to our knowledge, this study was the first study carried out in Egypt. We aimed to study the frequency of epilepsy among children with $\mathrm{CP}$ and various risk factors that affect the development of seizures.

\section{Patients and methods}

\section{Study area}

This study was carried out in two different areas in Egypt. The first was New Valley, which represents about $44 \%$ of the area of Egypt. It is divided into the El-Kharga, El-Farafra, and El-Dakhla districts. El-Kharga is far away from the Nile Valley and has different geographic, social, economic, and cultural characteristics. The second area was El-Quseir city, one of largest cities of the Red Sea Governorate. Its surface area is about $119,000 \mathrm{~km}^{2}$, and it lies directly on the Red Sea. ${ }^{6,10}$

\section{Sample}

In a cross-sectional, descriptive, population-based and casecontrol study, 98 children with CP (with or without epilepsy) were compared with 180 children without $\mathrm{CP}$ or seizures. The children were collected from two regions in Egypt, Al-Kharga District-New Valley and El-Quseir city-Red Sea, through two large projects carried out to detect the epidemiology of major neurological disorders. ${ }^{11,12}$ All inhabitants who have been living in Al-Kharga District-New Valley $(25,540)$ and El-Quseir city $(33,285)$ for at least 6 months at the time of the interview were included as a sampling frame to identify the potentially eligible population of children and adults with $\mathrm{CP}$ in defined areas. ${ }^{6,13}$ Screening of all households door to door (including every door) was done using a simple standardized Arabic screening questionnaire designed specifically for this study to pick up different neurological disorders, including CP cases. ${ }^{12}$ The control group was chosen from same population with matched sex, age, education level, and sociodemographic ${ }^{14}$ state.

\section{Definitions}

CP was defined as motor disabilities caused by nonprogressive damage to the developing brain. ${ }^{15} \mathrm{CP}$ is divided into the spastic, dyskinetic, and ataxic subtypes. ${ }^{16}$ The spastic subtype is further divided into unilateral (limbs on one side of the body are involved) and bilateral (limbs on both sides of the body are involved) types. The spastic bilateral type was further subdivided into quadriplegia and diplegia. ${ }^{6}$
Epilepsy was diagnosed according to Commission of Classification and Terminology of the International League Against Epilepsy. ${ }^{17}$ Active epilepsy was considered when two or more unprovoked seizures occurred during the previous year. ${ }^{6,16}$

The Standardized, Valid Arabic Version ${ }^{18}$ of the StanfordBinet scale (4th edition) ${ }^{19}$ was used to assess intelligence quotient (IQ). Total IQ was classified according to Melika ${ }^{18}$ into mentally retarded including those with IQ $>67$, slow learner (IQ =68-78), below-average intelligence (IQ =79-88), average intelligence (IQ =89-110), above-average intelligence (IQ =111-120), excellent intelligence (IQ =121-131), and genius (IQ =132). The Stanford-Binet scale was done for $60.2 \%(n=59)$ of case patients and $22.2 \%(n=40)$ of control patients. The children with $\mathrm{CP}$ or from the control group were chosen randomly, as every fourth child, and if that child refused, the second child was chosen.

Interictal electroencephalography (EEG) and computed tomography (CT) head scans or cranial magnetic resonance imaging (MRI) findings were evaluated. Cranial CT was performed with $1 \mathrm{~cm}$ thick slices using Hitachi Radix Turbo (Hitachi Ltd, Tokyo, Japan), brain MRI was used to acquire T1- and T2-weighed axial and coronal and T1-weighed sagittal images, using Picker 1-Tesla Vista HPQ (Picker International, Cleveland, OH, USA).

The following data were ascertained: type of CP, type of epilepsy, age, sex, age of onset of seizures, and sociodemographic ${ }^{14}$ state.

A structured questionnaire also was filled out face to face, and mothers' past medical and obstetrics histories were obtained. Available birth records of the children with $\mathrm{CP}$ were reviewed, including information regarding the health of the mother prior to the delivery and during pregnancy, family history of seizures, and the external factors occurring during the pregnancy and delivery. Specific complications of pregnancy encompassing abortion, hemorrhage in late pregnancy, premature rupture of membranes, and preterm labor ( $<32$ weeks of pregnancy) were examined. Additional variables were examined in relation to labor, including prolonged labor and meconium staining of liquor. In addition, postpartum variables, including low-birth-weight babies $(<2.5 \mathrm{~kg}$ at birth), birth asphyxia, prolonged jaundice, neonatal sepsis, other infections, neonatal seizure, and trauma, were examined.

EEG date and CT head scans or cranial MRI findings were evaluated. Cranial CT was performed with $1 \mathrm{~cm}$ thick slices using Hitachi Radix Turbo, and brain MRI was performed to acquire T1 - and T2-weighed axial and coronal and 
T1-weighed sagittal images, using a Picker 1-Tesla Vista HPQ. Then the patients were divided into three groups: epileptic patients with $\mathrm{CP}$, nonepileptic patients with $\mathrm{CP}$, and a healthy control group (without $\mathrm{CP}$ or seizures). Those groups were compared on the basis of clinical types, EEG, and cranial imaging findings.

\section{Ethics}

The Ethics Committee of Assiut University in Egypt approved the two studies (projects). Informed written consent was obtained from the Health Institute and from each patient's family (responsible person in each family).

\section{Statistical methods}

SPSS for Windows version 16 (IBM Corporation, Armonk, NY, USA) was used for data analysis. Prevalence rates were presented with binomial exact $95 \%$ confidence intervals. The chi square test, independent sample $t$ test, or one-way ANOVA test, followed by a post hoc test, were used to analyze differences in proportions between groups. Multivariate logistic regression was used to detect the influence of different risk factors for the development of epilepsy. Odds ratio and 95\% confidence interval were calculated from the model. All $P$ values were two-sided, and statistical significance was defined as $P<0.05$.

\section{Results}

Ninety-eight patients (52 boys, 46 girls) with CP were recruited. They included 48 patients $(48.9 \%)$ who had CP with epilepsy and 50 (51.02\%) CP patients without epilepsy compared with 180 healthy children. Other factors associated with the occurrence of epilepsy in children with CP were also analyzed (Table 1). Mental subnormality (mentally retarded, including those with IQ >67) according to the Stanford-Binet scale was observed more frequently in children with epilepsy than in those without epilepsy ( $84.6 \%$ versus $66.7 \%$ ). Sex, abnormal neuroimaging results, and family history of seizure disorders were not associated with the development of epilepsy, but neonatal seizure was significantly higher among the patients in the $\mathrm{CP}$ with epilepsy group than other groups. Abnormal MRI results included brain atrophic and white matter changes.

The frequency of epilepsy was highest in patients with spastic quadriplegic type disease (58.3\%; Table 2).

Multinomial logistic regression was used to assess the relationship between risk factors and $\mathrm{CP}$ with epilepsy (Table 3).

\section{Discussion}

Epilepsy affected $48.9 \%$ of children with $\mathrm{CP}$ in the present study. These results were similar to those from other studies. ${ }^{2,5,7,8,20}$ This was explained by the fact that children with CP might suffer extensive brain injury including to the cortex, deep white matter, and central nuclei, and therefore they are liable to develop epilepsy. ${ }^{16}$

In the present study, the frequency of epilepsy varied with the different forms of CP $(58.3 \%$ for spastic quadriplegic, $27 \%$ for mixed, $8.3 \%$ for spastic hemiplegic, $4.2 \%$ for dystonic type, and $2.1 \%$ for spastic diplegic). The frequency of epilepsy varied by CP subtype. When comparing and/or

Table I Demographic data of children and factors associated with development among CP

\begin{tabular}{|c|c|c|c|c|}
\hline Factor & $\begin{array}{l}\text { CP with epilepsy } \\
(n=48)\end{array}$ & $\begin{array}{l}\text { CP without } \\
\text { epilepsy }(n=50)\end{array}$ & $\begin{array}{l}\text { Control without } \\
\text { CP or epilepsy } \\
(n=\mid 80)\end{array}$ & $P$-value \\
\hline Age, mean $\pm S D$ & $7.97 \pm 4.741$ & $7.91 \pm 4.821$ & $7.19 \pm 2.712$ & 0.248 \\
\hline Sex, M/F & $28 / 20$ & $24 / 26$ & $86 / 94$ & 0.416 \\
\hline Abnormal MRI & $22(45.8 \%)$ & $21(42 \%)$ & - & 0.242 \\
\hline Positive family history & $3(1 \mathrm{I} .1 \%)$ & I (4\%) & & 0.335 \\
\hline Neonatal seizures & $6(12.5 \%)$ & I (2\%) & $5(2.8 \%)$ & 0.009 \\
\hline Total IQ & & & & 0.0001 \\
\hline Mentally retarded $(\leq 67)$ & $22(84.6 \%)$ & $22(66.7 \%)$ & 0 & \\
\hline Slow learners (68-78) & $2(7.7 \%)$ & $6(18.2 \%)$ & I $(2.5 \%)$ & \\
\hline Below-average intelligence (79-88) & 0 & $2(6.1 \%)$ & 7 (I7.5\%) & \\
\hline Average intelligence (89-I I0) & $2(7.7 \%)$ & $3(9.1 \%)$ & $26(65 \%)$ & \\
\hline Above-average intelligence $(\mathrm{II}|-| 20)$ & 0 & 0 & 0 & \\
\hline Excellent intelligence $(|2|-|3|)$ & 0 & 0 & $6(15 \%)$ & \\
\hline
\end{tabular}

Notes: Unless otherwise indicated, data are expressed as mean \pm SD or number and percentage done. IQ was performed for 26 patients with CP with epilepsy, 33 patients with CP without epilepsy, and 40 control patients. Abnormal MRI refers to brain atrophy and white matter changes.

Abbreviations: MRI, magnetic resonance imaging; M, male; F, female; CP, cerebral palsy; IQ, intelligence quotient; SD, standard deviation. 
Table 2 Frequency of epilepsy in relation to types of CP

\begin{tabular}{llll}
\hline Type of CP & $\begin{array}{l}\text { Total CP } \\
(\mathbf{n = 9 8 )}\end{array}$ & $\begin{array}{l}\text { CP with } \\
\text { epilepsy }(\mathbf{n}=\mathbf{4 8})\end{array}$ & $\begin{array}{l}\text { CP without } \\
\text { epilepsy (n=50) }\end{array}$ \\
\hline Spastic diplegia & $7(7.1 \%)$ & $\mathrm{I}(2.1 \%)$ & $6(12 \%)^{*}$ \\
Spastic hemiplegia & $14(14.3 \%)$ & $4(8.3 \%)$ & $10(20 \%)^{*}$ \\
Dystonic & $2(2.04 \%)$ & $2(4.2 \%)$ & 0 \\
Spastic quadriplegic & $45(45.9 \%)$ & $28(58.3 \%)^{*}$ & $17(34 \%)$ \\
Ataxic & $4(4.1 \%)$ & 0 & $4(8 \%)$ \\
Mixed & $26(26.5 \%)$ & $13(27.1 \%)$ & $13(26 \%)$ \\
\hline
\end{tabular}

Note: $* P<0.05$, from chi-square and Fisher's exact tests.

Abbreviation: $\mathrm{CP}$, cerebral palsy.

pooling data between several registers, Gururaj et $\mathrm{al}^{20}$ reported that spastic tetraplegia was the commonest type of CP with epilepsy, and spastic diplegia was the commonest type of CP in a group of patients with CP without epilepsy. Surveillance of Cerebral Palsy in Europe collaborators reported that children who were described as having diplegic or tetraplegic spastic CP were more liable to have epilepsy. ${ }^{21}$

Epidemiological study has revealed that cognitive impairment is a very common occurrence in CP children. ${ }^{22}$ Epilepsy in children with $\mathrm{CP}$ also has been related to impaired intellectual performance. ${ }^{5}$ In the present study, mental retardations were reported in $84.6 \%$ in patients with CP with epilepsy versus $66.7 \%$ among patients with CP without epilepsy. That matched with other studies. ${ }^{5,23}$ Vargha-Khadem et $\mathrm{l}^{24}$ reported that in patients, the presence of epilepsy is clearly associated with more severe and increasing cognitive difficulties, and Süssová et $\mathrm{al}^{25}$ reported that mental subnormality was more common in children with epilepsy than in those without epilepsy. Again, that could be explained by the fact that children with CP might suffer extensive brain injury including cortex, deep white matter, and central nuclei, and therefore are vulnerable to mental retardation and epilepsy. ${ }^{16}$ Hence,

Table 3 Analysis logistic regression for the association between $\mathrm{CP}$ with epilepsy and some risk factors

\begin{tabular}{lllll}
\hline CP with epilepsy & Significance & $\begin{array}{l}\text { Odds } \\
\text { ratio }\end{array}$ & \multicolumn{2}{c}{$\begin{array}{l}\text { 95\% confidence } \\
\text { interval }\end{array}$} \\
\cline { 3 - 5 } & & & $\begin{array}{l}\text { Lower } \\
\text { bound }\end{array}$ & $\begin{array}{l}\text { Upper } \\
\text { bound }\end{array}$ \\
\hline Male sex & 0.192 & 1.599 & 0.790 & 3.239 \\
Cesarean section & 0.064 & 2.719 & 0.951 & 7.771 \\
Prolonged labor & 0.304 & 2.642 & 0.415 & 16.819 \\
Prematurity and low & 0.0001 & 0.190 & 0.081 & 0.445 \\
birth weight babies & & & & 0.768 \\
Neonatal seizures & 0.022 & 0.165 & 0.036 & 0.688 \\
Jaundice & 0.012 & 0.18 & 0.047 & 0.680 \\
Cyanosis & 0.002 & 0.263 & 0.114 & 0.608 \\
\hline
\end{tabular}

Abbreviation: $\mathrm{CP}$, cerebral palsy. an early intervention with treatment of epilepsy prevents further progression of neuronal injury, with subsequent cognitive impairment caused by uncontrolled seizures, among those patients. ${ }^{6}$

Data regarding additional perinatal factors that might contribute to the pathogenesis of seizures in patients with $\mathrm{CP}$ are relatively scarce, and most studies refer to either CP in general or epilepsy in the general population, rather than to epilepsy in children with CP. ${ }^{26}$ The presence of prematurity and low birth weight was strongly predictive for the subsequent occurrence of epilepsy among CP children in the present study. That was matched with that fact that these studies consistently show that low birth weight and prematurity are risk factors for both epilepsy and $\mathrm{CP} .22,27,28$

With regard to neonatal seizures, in these studies, their presence was predicatively associated with occurrence of epilepsy among CP cases. A strong association of neonatal seizures with epilepsy has been already reported by Nelson and Ellenberg, during the Collaborative Perinatal Project of the National Institutes of Health, summarizing 54,000 singleton pregnancies between 1959 and 1966. ${ }^{29}$ Subsequently, additional retrospective studies clearly demonstrated that in children with $\mathrm{CP}$, a history of neonatal seizures was strongly predictive for future development of epilepsy. ${ }^{8,26,27,30}$ The presence of neonatal seizure was considered to be a factor for subsequent development of neurological disabilities (mental retardation, $\mathrm{CP}$, or epilepsy). ${ }^{8}$ Levene $^{31}$ reported that neonatal seizures had an adverse effect on neurodevelopmental progression and may predispose to cognitive, behavioral, or epileptic complications later in life.

In this study, cyanosis of child at birth and neonatal jaundice were found to be significant risk factors for developing epilepsy in these children with $\mathrm{CP}$ when analyzed using multivariate logistic regression. We considered cyanosis to be a picture of respiratory distress in children because we have no sufficient data or recorded reports for these children. However, respiratory distress was significantly associated with the occurrence of $\mathrm{CP}$. In addition, apnea requiring ventilation therapy appeared to be associated with the occurrence of $\mathrm{CP},{ }^{32}$ although it was not assessed well in this study. Prolonged jaundice may be responsible for $\mathrm{CP}$, although jaundice attributed to presence of meconium staining of the amniotic fluid is more likely to indicate a sign of intrapartum hypoxia and was more common in the CP cases. ${ }^{33}$

These risk factors, which might affect the development of seizures, lead to more deterioration in CP cases, although it is nonprogressive disease. 


\section{Conclusion}

Epilepsy among children with $\mathrm{CP}$ is common and represents $48.9 \%$ of children with CP. The observed relationship between epilepsy and associated impairments was as predicted. However, it requires longitudinal studies of children with $\mathrm{CP}$ and epilepsy to further improve our understanding of the relationship between epilepsy and CP. In addition, further studies concerning a possible risk of epilepsy development and its relationship with the EEG and cranial imaging findings may help in presenting the other risk factors involved and the factors affecting the prognosis of $\mathrm{CP}$ and understanding of the cause of epilepsy in CP.

\section{Disclosure}

The authors report no conflicts of interest in this work.

\section{References}

1. Hadjipanayis A, Hadjichristodoulou C, Youroukos S. Epilepsy in patients with cerebral palsy. Dev Med Child Neurol. 1997;39(10):659-663.

2. Sellier E, Uldall P, Calado E, et al. Epilepsy and cerebral palsy: characteristics and trends in children born in 1976-1998. Eur J Paediatr Neurol. 2012;16(1):48-55.

3. Okumura A, Hayakawa F, Kato T, Kuno K, Watanabe K. Epilepsy in patients with spastic cerebral palsy: correlation with MRI findings at 5 years of age. Brain Dev. 1999;21(8):540-543.

4. Senbil N, Sonel B, Aydin OF, Gürer YK. Epileptic and non-epileptic cerebral palsy: EEG and cranial imaging findings. Brain Dev. 2002;24(3):166-169.

5. Kwong KL, Wong SN, So KT. Epilepsy in children with cerebral palsy. Pediatr Neurol. 1998;19(1):31-36.

6. El-Tallawy HN, Farghaly WM, Shehata GA, Metwally NA, Rageh TA, Abo-Elfetoh N. Epidemiology of cerebral palsy in El-Kharga District-New Valley (Egypt). Brain Dev. 2011;33(5):406-411.

7. Hagberg G, Hagberg G, Olow I. The changing panorama of cerebral palsy in Sweden 1954-1970. II. Analysis of the various syndromes Acta Paediatr Scand. 1975;64(2):193-200.

8. Kułak W, Sobaniec W. Risk factors and prognosis of epilepsy in children with cerebral palsy in north-eastern Poland. Brain Dev. 2003;25(7):499-506.

9. Engel J Jr. A Greater Role for Surgical Treatment of Epilepsy: Why and When? Epilepsy Curr. 2003;3(2):37-40.

10. Gaber SM, Aly SM, Masood KA. Center of information and decision on making, red sea governorate achievement index. Egypt, Cairo: Dar El-Maref Publishing, 2010. Arabic.

11. El Tallawy HN, Farghaly WM, Metwaly NA, et al. Door-to-door survey of major neurological disorders in Al Kharga District, New Valley, Egypt: methodological aspects. Neuroepidemiology. 2013;5(3): 185-190.

12. El Tallawy HN, Farghaly WM, Rageh TA, et al. Epidemiology of major neurological disorders project in A1 Kharga district, New Valley, Egypt. Neuroepidemiology. 2010;35(4):291-297.
13. Tallawy HN, Farghaly WM, Rageh TA, et al. Door-to-door survey of major neurological disorders (project) in Al Quseir City, Red Sea Governorate, Egypt. Neuropsychiatr Dis Treat. 2019:767-771.

14. Fahmy S, El-Sherbini AF. Determining simple parameters for social classifications for health research. Bull High Inst Public Health. 1983;13:95-108

15. Bax MC. Terminology and classification of cerebral palsy. Dev Med Child Neurol. 1964;6:295-297.

16. Andersen GL, Irgens LM, Haagaas I, Skranes JS, Meberg AE, Vik T. Cerebral palsy in Norway: prevalence, subtypes and severity. Eur $J$ Paediatr Neurol. 2008;12(1):4-13.

17. Proposal for revised clinical and electroencephalographic classification of epileptic seizures. From the Commission on Classification and Terminology of the International League Against Epilepsy. Epilepsia. 1981;22(4):489-501.

18. Melika LK. The Stanford-Binet Intelligence Scale, Arabic Examiner's Handbook. 4th ed. Egypt, Cairo: Dar El-Maref Publishing; 1998.

19. Delany EA, Hopkins TF. The Stanford-Binet Intelligence Scale: Examiner's Handbook. 4th ed. Chicago, IL, USA: Riverside Publishing Co; 1986

20. Gururaj AK, Sztriha L, Bener A, Dawodu A, Eapen V. Epilepsy in children with cerebral palsy. Seizure. 2003;12(2):110-114.

21. Prevalence and characteristics of children with cerebral palsy in Europe. Dev Med Child Neurol. 2002;44(9):633-640.

22. Odding E, Roebroeck ME, Stam HJ. The epidemiology of cerebral palsy: incidence, impairments and risk factors. Disabil Rehabil. 28, 2006;28(4):183-191.

23. Jaseja H. Cerebral palsy: Interictal epileptiform discharges and cognitive impairment. Clin Neurol Neurosurg. 2007;109(7):549-552.

24. Vargha-Khadem F, Isaacs E, van der Werf S, Robb S, Wilson J. Development of intelligence and memory in children with hemiplegic cerebral palsy. The deleterious consequences of early seizures. Brain. 1992;115 Pt 1:315-329.

25. Süssová J, Seidl Z, Faber J. Hemiparetic forms of cerebral palsy in relation to epilepsy and mental retardation. Dev Med Child Neurol. 1990;32(9):792-795.

26. Zelnik N, Konopnicki M, Bennett-Back O, Castel-Deutsch T, Tirosh E. Risk factors for epilepsy in children with cerebral palsy. Eur J Paediatr Neurol. 2010;14(1):67-72.

27. Sun Y, Vestergaard M, Pedersen CB, Christensen J, Olsen J. Apgar scores and long-term risk of epilepsy. Epidemiology. 2006;17(3): 296-301.

28. Ehrenstein V, Sørensen HT, Pedersen L, Larsen H, Holsteen V, Rothman KJ. Apgar score and hospitalization for epilepsy in childhood: a registry-based cohort study. BMC Public Health. 2006;6:23.

29. Nelson KB, Ellenberg JH. Antecedents of seizure disorders in early childhood. Am J Dis Child. 1986;140(10):1053-1061.

30. Ronen GM, Buckley D, Penney S, Streiner DL. Long-term prognosis in children with neonatal seizures: a population-based study. Neurology. 2007;69(19):1816-1822.

31. Levene M. The clinical conundrum of neonatal seizures. Arch Dis Child Fetal Neonatal Ed. 2002;86(2):F75-F77.

32. Takahashi R, Yamada M, Takahashi T, et al. Risk factors for cerebral palsy in preterm infants. Early Hum Dev. 2005;81(6):545-553.

33. Oztürk A, Demirci F, Yavuz T, et al. Antenatal and delivery risk factors and prevalence of cerebral palsy in Duzce (Turkey). Brain Dev. 2007;29(1):39-42.

\section{Publish your work in this journal}

Neuropsychiatric Disease and Treatment is an international, peerreviewed journal of clinical therapeutics and pharmacology focusing on concise rapid reporting of clinical or pre-clinical studies on a range of neuropsychiatric and neurological disorders. This journa is indexed on PubMed Central, the 'PsycINFO' database and CAS

\section{Dovepress}

The manuscript management system is completely online and includes a very quick and fair peer-review system, which is all easy to use. Visit http://www.dovepress.com/testimonials.php to read real quotes from published authors. 